\title{
Effect of Sex Hormones on Rat Liver Cytosolic Alcohol Dehydrogenase Activity
}

\author{
Saori Harada, ${ }^{*}$ Kaoru TaChIYAShiki** and Kazuhiko Imaizumi \\ Department of Living and Health Sciences, Joetsu University of Education, \\ Joetsu, Niigata 943-8512, Japan
}

(Received May 6, 1998)

\begin{abstract}
Summary Rat liver cytosolic alcohol dehydrogenase (ADH) activity is known to be significantly higher in females than in males. To elucidate a possible mechanism of sex difference in the ADH activities, we studied the in vivo effects of the administrations of $\beta$-estradiol, progesterone or testosterone, and castrations (orchiectomy and ovariectomy) on the ADH activities in male and female Sprague-Dawley adult rats. Furthermore, we studied the ADH activities in six liver portions of sham-operated male, orchiectomized male, and female rats. The ADH activities were higher in orchiectomized male rats than in sham-operated male rats. These results were observed in all liver portions. The administration of testosterone $(5 \mathrm{mg} / \mathrm{kg} \mathrm{BW}$, twice a day for $7 \mathrm{~d})$ to orchiectomized male rats significantly decreased $\mathrm{ADH}$ activities. The ADH activities in ovariectomized female rats were comparable with those in sham-operated female rats. The administration of $\beta$-estradiol ( $50 \mu \mathrm{g} / \mathrm{kg} \mathrm{BW}$, once every $2 \mathrm{~d}$ for $20 \mathrm{~d}$ ) or progesterone $(75 \mu \mathrm{g} / \mathrm{kg} \mathrm{BW}$, once every $2 \mathrm{~d}$ for $20 \mathrm{~d}$ ) to rats increased the ADH activities in males more than in females. These results suggest that the inhibitory action of androgen and the slight facilitatory actions of progestin and estrogen are involved in the mechanism of sex difference in adult rat liver cytosolic $\mathrm{ADH}$ activity.
\end{abstract}

Key Words alcohol dehydrogenase, castrations, sex hormones, hormonal regulations of ethanol metabolism in rats

It is generally accepted that the first step in the major route for the metabolism of ethanol in liver is catalyzed by alcohol dehydrogenase $\mathrm{ADH}$; alcohol: $\mathrm{NAD}^{+}$oxidoreductase, EC 1.1.1.1) (1). Although the exact physiological role of $\mathrm{ADH}$ is uncertain, it catalyzes the oxidation or the reduction of several physiological

* Present address: Doctoral Program of Joint Graduate School in Science of School Education, Hyogo University of Teacher Education, Yashiro-cho, Katou-gun, Hyogo 673-1494, Japan.

** Correspondence and reprint request: e-mail: kaoru@juen.ac.jp; Tel and Fax: $+81-255-21-3410$ or $+81-255-21-3580$. 
endogeneous steroidal and nonsteroidal substrates, in addition to ethanol (2-5). Five chief classes of mammalian ADH isozyme have been identified, which differ in their kinetic properties, substrate specificities, and tissue distribution $(2,4)$. In the case of rat $\mathrm{ADH}$, the kinetic properties of the different enzymes seem to vary in a manner similar to those of human $\mathrm{ADH}$ (4). It appears likely that the rat ADH enzymes could also be classified by the system suggested for human ADHs (4). Class I ADH enzymes are very sensitive to pyrazole inhibition and have a strong affinity for ethanol (human $\mathrm{ADH}$ isozymes with $\alpha, \beta$, and $\gamma$ subunits and rat ADH-3); class III ADH is nearly insensitive to pyrazole and has a very low affinity for ethanol (human $\chi-\mathrm{ADH}$ and rat $\mathrm{ADH}-2$ ); and class II ADH enzymes have intermediate properties (human $\pi$-ADH and rat $\mathrm{ADH}-1)(4,5)$.

Class I ADH in the rat liver is the most abundant enzyme, accounting for the great majority (about 96\%) of total ADH activity $(5,6)$. It exists as a dimer of two $40 \mathrm{kDa}$ subunits, each containing two atoms of zinc, one which is directly involved in catalysis and the other appears to have a structural role (7). The gene of the class I ADH is expressed at high levels in liver but at low levels in other tissues, and it is developmentally regulated (3). Evidence also suggests that the gene is hormonally regulated (5-7). The liver ADH activity in rats is affected by a variety of hormones. Steroid hormones such as glucocorticoids and retinoic acid appear to positively influence the expression of the mammalian class I gene $(3,7)$. Hypophysectomy, thyroidectomy, and castration each increases enzyme activity, which is then suppressed by growth hormone (8-19). Adrenalectomy had no effect on its activity (3). In primary rat hepatocyte cultures, growth hormone and insulin-like growth factor I increase ADH activity and ADH mRNA content $(20,21)$.

On the other hand, stress, which stimulates the hypothalamo-hypophysealadrenocortical axis and the sympathetic nervous system but decreases circulating testosterone levels, increases liver ADH activity $(22-24,27)$. Our previous preliminary studies also have shown that liver cytosolic ADH activity and mitochondrial aldehyde dehydrogenase activity in male rats were significantly lower than in female rats $(25,26)$. These findings show that modulation of hepatic class I ADH activity and ethanol metabolism in liver is regulated by sex hormones in rats $(5,8,10,15)$. It is essential for the complete elucidation of the regulation by sex hormones of ethanol metabolism in liver to study systematically the effects of sex hormones on liver ADH activity $(5,25,26,28)$. To clarify further the possible mechanism of sex difference of ADH activity, therefore, we studied 1) the effects of orchiectomy or ovariectomy on liver ADH activity, and 2) the effects of the administration of testosterone, $\beta$-estradiol, or progesterone on liver ADH activities in male and female rats. Furthermore, we reexamined the sex difference of liver ADH activity. 


\section{MATERIALS AND METHODS}

1. Experimental animals and diets. Specific pathogen-free male and female Sprague-Dawley rats (6-8 weeks old: CLEA Japan, Tokyo) were normally housed in a cage at a controlled temperature $\left(23-25^{\circ} \mathrm{C}\right)$ and a relative humidity $(50-60 \%)$ environment with fixed light-dark cycles [08:00 to 20:00 (light) and 20:00 to 08:00 (dark)] (29,30). Food (CE-2 cubic type, CLEA Japan) and once-boiled tap water were given to the rats ad libitum. All rats were weighed daily during the experimental period.

Four parts of an experiment were carried out: 1) comparison between male rats and female rats on liver ADH activities, 2) effects of castrations (orchiectomy or ovariectomy) to male and female rats on liver ADH activities, 3) effects of the administration of testosterone to the orchiectomized and sham-operated male rats on liver ADH activities, and 4) effects of the administration of $\beta$-estradiol or progesterone on liver ADH activities in male and female rats. We also studied the liver portion dependence of liver ADH activity. The cytosolic samples were prepared from 1) lobus hepatis sinistra lateralis, 2) lobus hepatis sinistra medialis, 3) lobus hepatis dextra medialis, 4) lobus hepatis dextra lateralis, 5) processus caudatus, and 6) processus papillaris.

The present studies were carried out according to the "Guiding Principles for the Care and Use of Animals in the Field of Physiological Sciences" of the Physiological Society of Japan (31). We performed the experiments with the least possible pain or discomfort to the animals $(29,30)$.

2. Animal treatments

1) Castrations (orchiectomy and ovariectomy): Under the method of Mezey et al $(12,24)$, some male rats were orchiectomized under ether anesthesia, and the other male rats had a sham surgical procedure consisting of dissection of the scrotum and manipulation of the testes with forceps $(12,24)$ and were used as controls. All rats were sacrificed $5-15 \mathrm{~d}$ after surgery.

In conformity with the methods of Tachiyashiki and Imaizumi (25) and of Teschke et al (32), some female rats were ovariectomized via a medial dorsal incision under sodium pentobarbital (dose: $50 \mathrm{mg} / \mathrm{kg}$ body weight) anesthesia. We used sodium pentobarbital as a general anesthetic instead of ether because the operation procedure was necessary for about $1 \mathrm{~h}$. After the ligature of uteri on both sides, ovaries were removed and the dorsal portion was closed with sutures $(25,32)$. The other female rats had a sham surgical procedure and were used as controls. All rats were sacrificed $7 \mathrm{~d}$ after surgery (25).

2) Administrations of testosterone, $\beta$-estradiol, or progesterone to rats: To investigate the effects of testosterone on rat liver ADH activity, orchiectomized and sham-operated male rats were treated with testosterone propionate (Nacalai Tesque, Kyoto) the day after surgery under the methods of Tachiyashiki and Imaizumi (25) and Teschke et al (32). Testosterone propionate was solubilized in sesame oil as a vehicle to obtain a testosterone concentration of $0.5 \%$ and administered by 
subcutaneous injection at a dose of $5 \mathrm{mg}$ per body weight of $\mathrm{kg}$ twice a day (06:00-07:00 and 18:00-19:00) for $7 \mathrm{~d}(25,26)$. All animals were sacrificed $2 \mathrm{~h}$ after the last injection.

Nonoperated male and female rats received $\beta$-estradiol or progesterone by subcutaneous injection to study the effects of estrogen or progestin on rat liver ADH activity $(25,26)$. In distilled water, $0.15 \% \quad \beta$-estradiol $(42 \mathrm{mg}$ estradiol $/ \mathrm{g}$ balance 2-hydroxypropyl- $\beta$-cyclodextrin (Sigma Chem., St. Louis)) and $0.15 \%$ progesterone ( $82 \mathrm{mg}$ progesterone/g balance 2-hydroxypropyl- $\beta$-cyclodextrin (Sigma Chem.)) was prepared and administered to rats in doses of $50 \mu \mathrm{g}$ and $75 \mu \mathrm{g}$ per $\mathrm{kg}$ of body weight (19) for $\beta$-estradiol and progesterone, respectively. Cyclodextrin was contained in $\beta$-estradiol and progesterone solutions. Therefore $1.1 \mathrm{mg}$ hydroxypropyl- $\beta$-cyclodextrin per $\mathrm{kg}$ of body weight was given to the corresponding control rats. The injections were given once every $2 \mathrm{~d}$ for $20 \mathrm{~d}$, and the rats were sacrificed to the next day after the last injection between 17:00 and 18:00 $(25,26,32)$.

3. Preparation of rat liver cytosolic fraction. The rats were sacrificed by decapitation, and the livers were immediately removed, weighed, and perfused with ice-cold $0.9 \% \mathrm{NaCl}$ solution. Ten percent liver homogenates were prepared in ice-cold $0.1 \%$ Triton $\mathrm{X}-100$ in $0.9 \% \mathrm{NaCl}$ solution. The homogenate was centrifuged at $7,000 \times g$ for $10 \mathrm{~min}$ at $5^{\circ} \mathrm{C}$. The pellet was discarded, and the supernatant was spun at $105,000 \times g\left(\right.$ Beckman XL-70, USA) for $60 \mathrm{~min}$ at $4^{\circ} \mathrm{C}$. The resulting supernatant cytosolic fraction was used for the determination of $\mathrm{ADH}$ activity $(25,26)$.

4. Measurement of rat liver ADH activity. Liver cytosolic ADH activities were measured spectrophotometrically at $340 \mathrm{~nm}$ at $38^{\circ} \mathrm{C}$. The reaction mixture was $2.5 \mathrm{~mL}$ and consisted of $60 \mathrm{~mm}$ glycine pyrophosphate buffer $(\mathrm{pH} 9.0), 80 \mathrm{~mm}$ semicarbazide solution, $12 \mathrm{~mm}$ GSH, $10 \mathrm{~mm}$ ethanol, $2.8 \mathrm{~mm} \mathrm{NAD}^{+}$, and 0.01 to $0.02 \mathrm{~mL}$ of the liver cytosol $(28-30,33,34)$. The rate of $\mathrm{NADH}$ formation in the absence of ethanol was subtracted as blank from the rate obtained in its presence. The ADH activities were then calculated from the molar extinction coefficient for NADH of $6.2 \mathrm{~mm}^{-1} \cdot \mathrm{cm}^{-1}$ at $340 \mathrm{~nm}$. The enzyme activities were expressed as the amount of enzyme that produces $1 \mathrm{~nm}$ of NADH per min per mg of protein.

We determined whether ADH activities of liver cytosolic fractions prepared in the present study are actually based on true class I ADH. As already described, the class I ADH accounts for the vast majority (about 96\%) of total ADH in the rat liver $(5,6)$. Therefore an $\mathrm{ADH}$ inhibitor, excess pyrazole (about 5-30 mm), was added to the reaction mixture for the ADH assay and the rate of NADH formation was measured. The liver cytosolic ADH activities in the presence of excess pyrazole were comparable with those in the absence of ethanol (data not shown). Furthermore, we determined the Michaelis constants $(\mathrm{Km})$ for ethanol and NAD (pH 9.0 and $38^{\circ} \mathrm{C}$ ). The $\mathrm{Km}$ values $(n=14$, means \pm SE) were obtained from the liver $\mathrm{ADH}$ activities of male rats and were estimated as $0.76 \pm 0.03 \mathrm{~mm}$ for ethanol and $0.10 \pm 0.004 \mathrm{~mm}$ for NAD. These results agreed with other published 


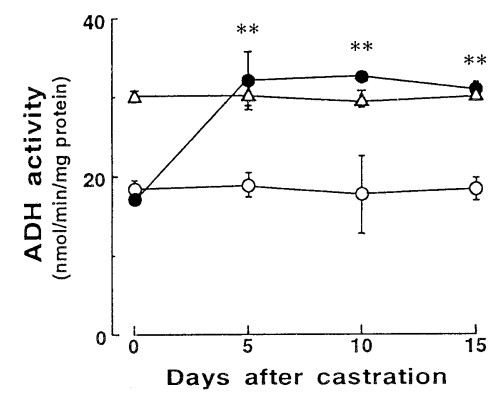

Fig. 1. Durations of liver ADH activity after the orchiectomy of male rats. Values: raeans \pm SE (3 animals in each group at each time point). $\bigcirc$ : sham-operated male rats, 0 : orchiectomized male rats, and $\triangle$ : female rats. ${ }^{* *} p<0.01$ (vs. $0 \mathrm{~d}$, by Bonferroni/Dunn's test).

data (35).

Liver cytosolic proteins were determined by the method of Lowry et al (36), using bovine serum albumin (Sigma Chem.) as a standard.

5. Measurement of the wet weights of visceral organs. After the decapitation, we weighed the wet weights of liver, adrenals, and thymus to clarify the effects of hormone administrations and of surgical stress.

6. Statistics. Data are presented as means \pm SE or means. A one-way analysis of variance (ANOVA) and two-way ANOVA were used to test for statistically significant differences. Post hoc analyses were performed with Dunnett's test or Bonferroni/Dunn's test. The differences were considered when $p$ was $<0.05$.

\section{RESULTS}

\section{Effects of orchiectomy and ovariectomy on rat liver ADH activity}

We investigated the duration of liver $\mathrm{ADH}$ activity after the castration (orchiectomy) of male rats. As shown in Fig. 1, the ADH activities were significantly higher than in sham-operated male rats at 5, 10, and $15 \mathrm{~d}$ after castration, and the $\mathrm{ADH}$ activities were comparable with those of female rats. These results indicate that the ADH activities have already been higher in orchiectomized male rats than in sham-operated male rats at $5 \mathrm{~d}$ after castration. Therefore we examined the effect of orchiectomy on the liver ADH activity in male rats at $10 \mathrm{~d}$ after surgery to keep the recovery period from surgery.

Figure 2 shows the effects of orchiectomy on liver ADH activity (A), on liver cytosolic protein content (B), on total liver ADH activity (C), and on total liver $\mathrm{ADH}$ activity per body weight (D). As shown in Fig. 2A, the liver ADH activities of orchiectomized male rats was 1.72 times significantly higher than in sham-operated male rats. The liver ADH activities of orchiectomized male rats were comparable with those of female rats. The liver cytosolic protein content, however, was significantly $9 \%$ lower in the orchiectomized male rats than in the sham-operated 

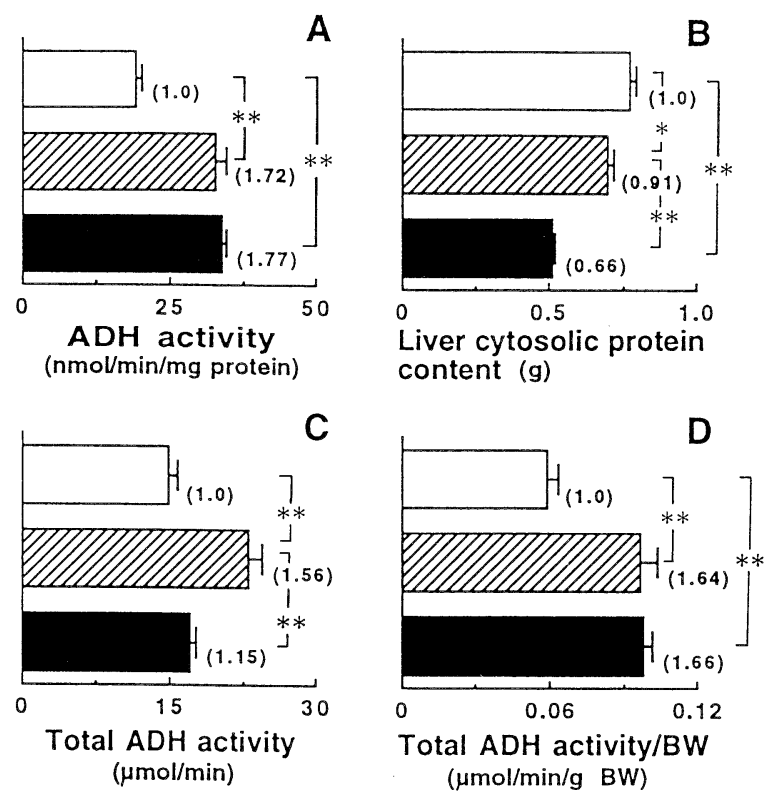

Fig. 2. Effects of orchiectomy on the liver ADH activity (A), on liver cytosolic protein content (B), on total liver ADH activity (C), and on total liver ADH activity per body weight (D). Values: means \pm SE (8 animals in each group). $\square$ : sham-operated male rats $(\mathrm{BW}=254 \pm 3 \mathrm{~g}), \mathbb{Z}$ : orchiectomized male rats $(\mathrm{BW}=240 \pm 4 \mathrm{~g})$, and female rats $(B W=177 \pm 2 \mathrm{~g})$. All rats were weighed just before the sacrifice. The data of sham-operated male rats were employed as the standard ratio. ${ }^{*} p<0.05$ and $* * p<0.01$ (by Bonferroni/Dunn's test).

male rats (Fig. 2B). To the contrary, the liver cytosolic protein content of the female rats was 0.66 times $(p<0.01)$ that of sham-operated male rats (Fig. $2 \mathrm{~B})$.

Total liver ADH activity was significantly 1.56 times higher in the orchiectomized male rats than in the sham-operated male rats (Fig. 2C). Furthermore, the total liver ADH activity per body weight was 1.64 times $(p<0.01)$ higher in the orchiectomized male rats than in the sham-operated male rats, and the value was comparable with that of female rats (Fig. 2D).

Next we studied the portion-dependence of liver ADH activities and cytosolic protein concentrations in the orchiectomized and sham-operated male rats. Moreover, the liver ADH activities and cytosolic protein concentrations in female rats are also studied. As shown in Fig. 3A, the liver ADH activities of orchiectomized male rats (II) were about 2.2 times systematically higher in all liver lobe portions and processes than in sham-operated male rats (I), and these results (II) were comparable to those (III) of female rats. ADH activities in all liver lobes and processes were nearly equal in each group (Fig. 3A, I-III). The liver cytosolic protein concentrations, however, were similar for all three groups (Fig. 3B, I-III) and were comparable among each group (Fig. 3B). 
A

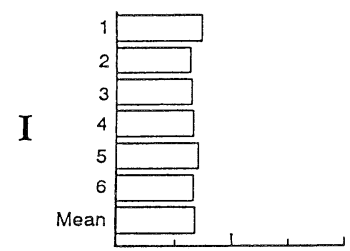

II

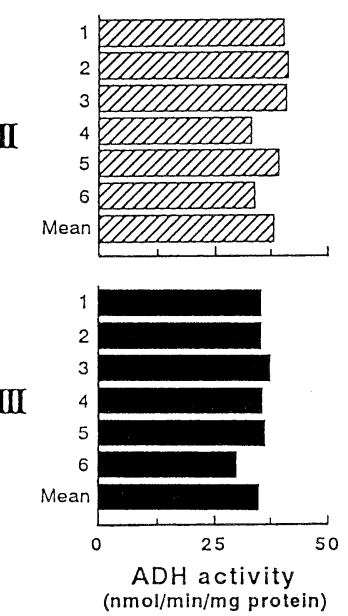

B
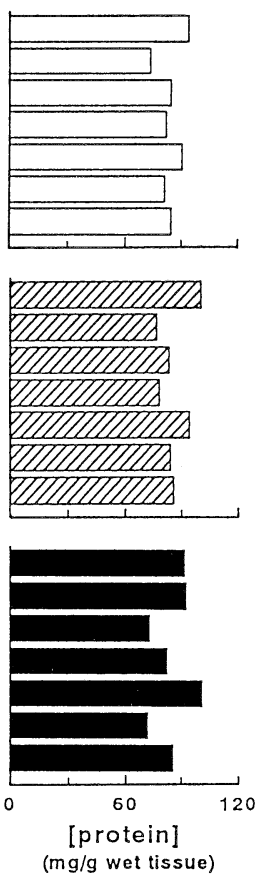

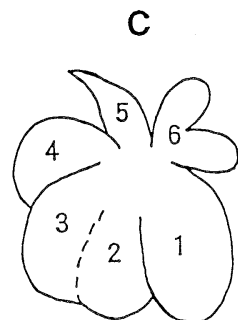

Fig. 3. Liver ADH activity (A), liver cytosolic protein concentration (B), and diagrammatic representation of a model of liver portion of rat (C). I: sham-operated male rats, II: orchiectomized male rats, and III: female rats. Values in A and B are shown as experimental data. C: lobus hepatis sinistra lateralis (1), lobus hepatis sinistra medialis (2), lobus hepatis dextra medialis (3), lobus hepatis dextra lateralis (4), processus caudatus (5), and processus papillaris (6).

As shown in Fig. 4A, the liver ADH activities in the ovariectomized female rats were almost similar to those in the sham-operated female rats. Similar results were observed in the liver cytosolic protein concentration (Fig. 4B). These results, therefore, suggested that the ovariectomy had no effect on the liver ADH activities.

Orchiectomy did not change liver and adrenal weights. However, thymus weight was 1.34 times significantly higher in orchiectomized male rats than in sham-operated male rats. On the contrary, ovariectomy did not change the three visceral organ wet weights (data not shown).

\section{Effect of testosterone on liver ADH activities in orchiectomized male rats}

We then studied the effect of testosterone administration on liver $\mathrm{ADH}$ activities in sham-operated male rats and orchiectomized rats. These data were evaluated by two-way ANOVA, and the ordinal interaction between two factors (castration and testosterone administration) was observed as statistically significant $(p<0.01)$. As 
A

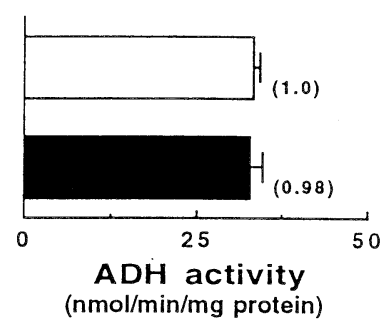

B

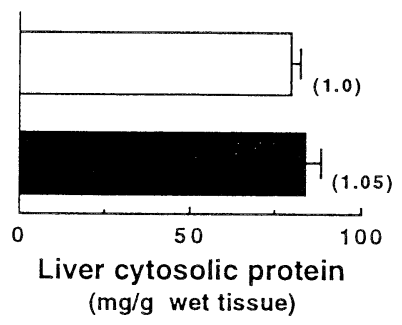

Fig. 4. Effects of ovariectomy in the liver ADH activity (A) and liver cytosolic protein concentration (B). Values: means \pm SE ( 3 animals in each group). $\square$ : sham-operated female rats $(B W=181 \pm 3 \mathrm{~g})$ and $\mathbf{\square}$ : ovariectomized female rats $(\mathrm{BW}=195 \pm 4 \mathrm{~g})$. All rats were weighed just before the sacrifice. Data in sham-operated female rats were employed as the standard ratio. Statistics: one-way ANOVA.

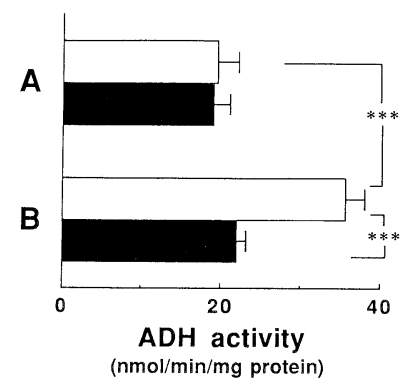

Fig. 5. Effects of testosterone on the liver ADH activity in sham-operated male rats (A) and orchiectomized male rats (B). Values: means \pm SE ( 7 animals in each group). (A) sham-operated male rats, $\square$ : testosterone-free group (BW=262 $\pm 3 \mathrm{~g}$ ) and testosterone administered group $(\mathrm{BW}=264 \pm 2 \mathrm{~g}$ ). (B) orchiectomized male rats, testosterone-free group ( $\mathrm{BW}=264 \pm 2 \mathrm{~g}$ ) and $\mathbf{\square}$ : testosterone-administered group $\left(\mathrm{BW}=256 \pm 2 \mathrm{~g}\right.$ ). All rats were weighed just before the sacrifice. ${ }^{* * *} p<0.001$ (by the subsequent one-way ANOVA test after the analyses of two-way ANOVA).

shown in Fig. 5A, the liver $\mathrm{ADH}$ activity did not change when the testosterone was administered to the sham-operated male rats. As shown in Fig. 5B, however, the administration of testosterone $(5 \mathrm{mg} / \mathrm{kg} \mathrm{BW})$ to the orchiectomized male rats significantly decreased the liver ADH activity to 0.61 times. The administration of testosterone to sham-operated and orchiectomized male rats did not change liver and adrenal weights. On the contrary, the thymus weight and the ratio of thymus weight per body weight were about $50 \%$ lower in the testosterone-treated rats than in the testosterone-untreated rats (data not shown).

\section{Effects of $\beta$-estradiol or progesterone on rat liver ADH activity}

As shown in Fig. 6A (a), the administration of $\beta$-estradiol $(50 \mu \mathrm{g} / \mathrm{kg} \mathrm{BW})$ or 
A
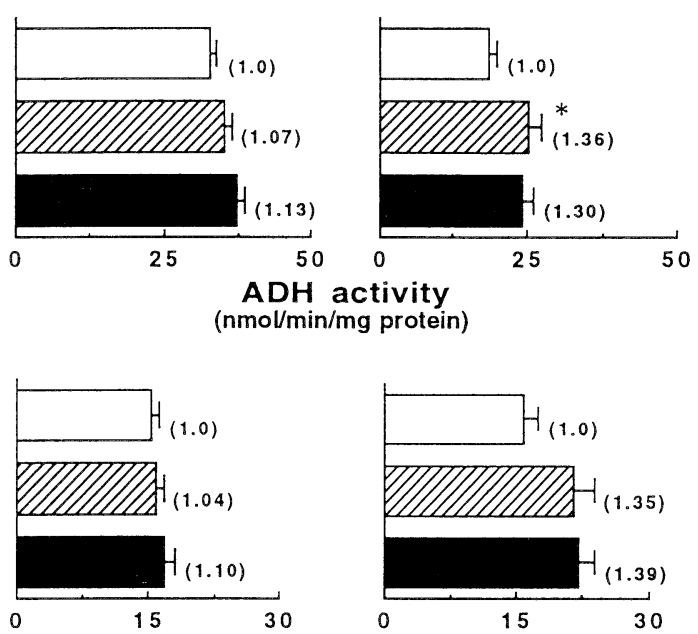

Total ADH activity $(\mu \mathrm{mol} / \mathrm{min})$

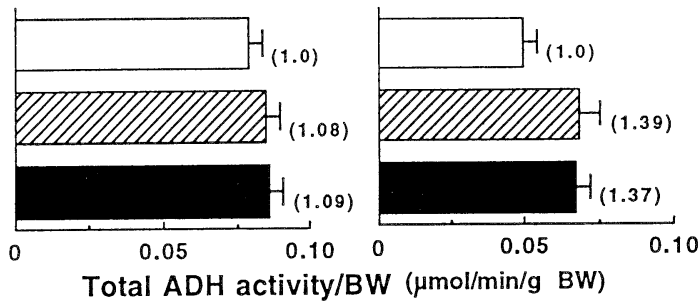

(a)

(b)

(c)

Fig. 6. Effects of $\beta$-estradiol and progesterone on liver ADH activity (a), total liver $\mathrm{ADH}$ activity (b), and total liver ADH activity per body weight (c) in female (A) and male (B) rats. Values: means \pm SE (7 animals in each group). $\square$ : control $[\mathrm{BW}=193 \pm 4 \mathrm{~g}$ (female) and $322 \pm 5 \mathrm{~g}$ (male) $]$; 四: $\beta$-estradiol-administered $(50 \mu \mathrm{g} / \mathrm{kg}$ $\mathrm{BW}$ ) group $[\mathrm{BW}=187 \pm 3 \mathrm{~g}$ (female) and $315 \pm 6 \mathrm{~g}$ (male)]; and $\mathbf{\square}$ : progesteroneadministered $(75 \mu \mathrm{g} / \mathrm{kg} \mathrm{BW})$ group $[\mathrm{BW}=194 \pm 4 \mathrm{~g}$ (female) and $328 \pm 7 \mathrm{~g}$ (male)]. All rats were weighed just before sacrifice. Data in the control were employed as the standard ratio. ${ }^{*} p<0.05$ (vs. control, by Dunnett's test).

progesterone $(75 \mu \mathrm{g} / \mathrm{kg} \mathrm{BW})$ to female rats slightly increased liver ADH activities to 1.07 and 1.13 times, respectively, as compared with the female control rats. But no significant effects of these sex hormones on liver ADH activities in female rats appeared. On the contrary, the administration of $\beta$-estradiol or progesterone to male rats markedly increased the liver ADH activities to $1.36(p<0.05)$ and 1.30 times, respectively, compared with the male control rats [Fig. 6B(a)]. Similar tendencies were also observed in total ADH activity per body weight [Fig. 6A(c) and $\mathrm{B}(\mathrm{c})]$.

Total liver $\mathrm{ADH}$ activities of female rats showed no significant change to the 
administration of $\beta$-estradiol or progesterone [Fig. 6A(b)]. Although the values were not significant among groups, the administration of $\beta$-estradiol or progesterone to male rats increased the total liver ADH activities to 1.35 and 1.39 times, respectively, as compared with the male control rats [Fig. 6B(b)]. Furthermore, male rats exhibited higher total liver ADH activity per body weight compared with female rats when the $\beta$-estradiol or progesterone was administered (Fig. 6B).

The administration of $\beta$-estradiol or progesterone to female and male rats resulted in no changes in liver and thymus weights. However, the administration of $\beta$-estradiol to male rats significantly increased adrenal weights $(p<0.05)$, and the administration of progesterone slightly decreased it (data not shown).

\section{DISCUSSION}

The purpose of the present study was to elucidate the in vivo effect of sex hormones on the cytosolic ADH activity in the livers of rats. Therefore we examined the in vivo effects of the ablation of testis or ovary and administration of sex-steroid hormones (testosterone, $\beta$-estradiol, and progesterone) on liver ADH activities in male and female rats.

The main findings of the present study: 1) orchiectomy significantly increased the liver ADH activity (Figs. 1 to 3), but ovariectomy had no effect on it (Fig. 4); 2) the $\mathrm{ADH}$ activities increased by orchiectomy were observed at least $5 \mathrm{~d}$ after orchiectomy (Fig. 1);3) the administration of testosterone to orchiectomized male rats significantly decreased the liver ADH activity, but no its activity of shamoperated male rats was induced by testosterone administration (Fig. 5); 4) the administration of $\beta$-estradiol significantly increased the liver ADH activity of male rats (Fig. 6).

The present studies demonstrate that testosterone is responsible for the decrease in ADH activity in male rats (Fig. 5), and $\beta$-estradiol and progesterone are responsible for a slight increase in ADH activity in female rats and male rats (Fig. 6). Our studies have also shown that testosterone, $\beta$-estradiol, or progesterone added in vitro does not change the liver ADH activity in male and female rats (data not shown). These results, therefore, suggest that effects of the ablation of gonadal organs and the administration of these sex-steroid hormones on the ADH activities are not mediated by a direct interaction between $\mathrm{ADH}$ molecules and these steroids. From these findings and suggestions, we must consider other possibilities as a possible mechanism of sex difference of liver ADH activity in rats. Recent studies show that the ADH gene is hormonally regulated in rat liver, and the expression of rat liver class I ADH gene is regulated by hormones $(3,5,14)$. In primary rat hepatocyte culture, growth hormone and insulin-like growth factor-I were shown to increase ADH activity and messenger RNA $(3,5)$. Furthermore, the effect of growth hormone on the increased synthesis of $\mathrm{ADH}$ in hepatocytes was shown to be at the transcriptional level $(3,5,35)$.

Potter et al (3) pointed out that the liver-enriched transcription factors, the 
CCAAT/enhancer-binding protein (C/EBP), the liver activator protein (LAP), the upstream stimulatory factor (USF), and the enhancer-site downstream binding protein (EDBP) bind to and activate the promoter of the rat class I ADH gene. The interaction of various transcription factors with specific sequences present in the promoters is thought to be an essential component of the regulatory machinery (1-3). Furthermore, many steroid hormones exert a dramatic effect on responsive genes through interaction with a receptor protein, which in turn binds to specific DNA sequences to promote transcription. Therefore, Potter et al (3) and Mezey et al (5) postulated that one or more of these nuclear transcription factors may mediate hormonal effects on the ADH gene $(3,5)$.

The transcriptional activation of a gene by hormone treatment would presumably involve interaction between a hormone-receptor complex and DNA sequences in the target gene (35). The present study showed that orchiectomy in male rats increased liver ADH activity and that testosterone administration suppressed the enhanced activity of liver ADH produced by orchiectomy (Fig. 5).

As already reported, ovariectomy increased ADH enzyme protein in male rats and decreased the rate of degradation without change of the rate of synthesis in the liver ADH of male rats (5). Generally, ADH is a cytosolic enzyme with a relatively long half-life of about $4 \mathrm{~d}$, and receptors for gonadal steroids are known to be contained in rat liver (35). Moreover, the $\mathrm{Km}$ values of $\mathrm{ADH}$ for ethanol and for $\mathrm{NAD}^{+}$were not affected by castration or testosterone administration (5). Therefore the changes in liver ADH activity after orchiectomy and the administration of testosterone are not associated with alterations in the $\mathrm{Km}$ values for ethanol and $\mathrm{NAD}^{+}$. Orchiectomy also decreased the plasma testosterone level to about $1 / 13$, with the control values, and when testosterone was administered to orchiectomized rats, the plasma testosterone concentration was about 6 times higher than in sham-operated control rats at the time of sacrificing (24).

From these results and suggestions, although the mechanism of its action is unknown, the liver ADH activity in male rats may be at least in part regulated at the transcription level of class I ADH gene to the response to plasma androgen level.

On the other hand, it is of interest to note that liver ADH activity may be regulated by more than one hormone, and the effect of the administration of one hormone on the enzyme activity may depend on its interaction with other hormones $(9,10,37)$. Many previous studies $(8,12,13,16,20-22)$ showed increases in liver $\mathrm{ADH}$ activity during uremia produced by partial nephrectomy after stress induced by immobilization and after hypophysectomy. Further, uremia and various forms of stress in man all result in a fall in plasma testosterone levels.

These observations suggest first that ADH activity is regulated by more than one hormone, and second that the effect of the administration of one hormone on enzyme activity may depend on its interaction with hormones (12). Among the best-known interactions are those between androgens and growth hormones $(9$, 10,37-39). For instance, pituitary growth hormone concentrations are higher in the male than in the female rat; orchiectomy in the male decreases growth hormone 
to the level it is in the female; and the administration of testosterone to the female increases growth hormone. Furthermore, the effect of growth hormone in decreasing ethylmorphine demethylation in normal male rats, but not in normal female rats, appears to be partly due to an effect of growth hormone antagonizing the stimulating action of testosterone on this microsomal enzyme $(12,40)$. Testosterone is thus known to enhance maximum growth hormone levels in man after various stimuli such as hypoglycemia (12). Furthermore, pituitary growth hormone concentrations are higher in the male rat than in the female rat; castration in the male decreases growth hormone to the female level, whereas the administration of testosterone to the female increases growth hormone (12). As shown in Figs. 2-4 and 6 , because testosterone and female hormones such as $\beta$-estradiol and progesterone appear to have opposing actions on liver ADH activity, the relative ratio of estradiol to testosterone may be an important determinant of the rate of ethanol metabolism $(12,40)$. Obviously, further studies are required in the female to more fully assess the regulation of liver $\mathrm{ADH}$ and the metabolism of ethanol and to assess the effect of drugs on these regulatory systems (40). However, the in vivo effects of the interaction of one hormone with others on liver ADH activity are still uncertain.

Most evidence gathered from kinetic studies, inhibitor studies, and comparisons of rates of ethanol oxidation in vivo with ADH activity in vitro supports the conclusion that under most circumstances the activity of $\mathrm{ADH}$ in liver plays an important role in regulating the rate at which ethanol is metabolized (35). In contrast to our present results, many situations lack a correlation between rate of ethanol elimination and liver ADH activity. These include an increased rate of ethanol elimination in association with a decreased enzyme activity after thyroxine administration $(5,17,35)$, and a normal rate in association with enhanced enzyme activity in experimental uremia (24). Increases in the rate of ethanol elimination after ethanol administration have been associated with changes in liver ADH activity in only a few, and most, studies $(24,35,37)$. Rachamin et al $(8)$ showed that liver ADH activity in orchiectomized male spontaneously hypertensive rats (SHR) was associated with a parallel increase in the rate of ethanol elimination. We are now studying the relation between ethanol metabolic rate and liver $\mathrm{ADH}$ activity in orchiectomized rats.

In conclusion, the inhibitory action of androgen and the slight facilitatory actions of progestin and estrogen may be involved in the mechanism of sex difference in adult rat liver cytosolic $\mathrm{ADH}$ activity.

We wish to thank Professor Mitsuko Okada (Faculty of Health and Living Sciences, Naruto University of Education) for her helpful advice and suggestions. Thanks are also extended to Ms. Jun Mizuide for her good cooperation. 


\section{REFERENCES}

1) Ceci JD, Lawther R, Duester G, Hatfield GW, Smith M, O'Malley MP, Felder MR. 1986. Androgen induction of alcohol dehydrogenase in mouse kidney. Studies with a cDNA probe confirmed by nucleotide sequence analysis. Gene 41: 217-224.

2) Cortese JF, Majewski JL, Crabb DW, Edenberg HJ, Yang VW. 1994. Characterization of $5^{\prime}$-flanking sequence of rat class I alcohol dehydrogenase gene. $J$ Biol Chem 269: 21898-21906.

3) Potter JJ, Mezey E, Cornelius P, Crabb DW, Yang VW. 1992. The first 22 base pairs of the proximal promoter of the rat class I alcohol dehydrogenase gene is bipartite and interacts with multiple DNA-binding proteins. Arch Biochem Biophys 295: 360-368.

4) Julia P, Parés X, Jörnvall H. 1988. Rat liver alcohol dehydrogenase of class III. Primary structure, functional consequences and relationships to other alcohol dehydrogenases. Eur J Biochem 172: 73-83.

5) Mezey E, Potter JJ, Yang VW. 1993. Hormonal regulation of the rat class I alcohol dehydrogenase gene. Alcohol Alcohol Suppl 2: 57-62.

6) Canto MF, Oliva MM, Potter JJ, Mezey E, Yang VW. 1992. Enhancer-site downstream binding protein activity is enriched in rat tissues that express the class I alcohol dehydrogenase gene. Biochem Biophys Res Commun 188: 684-689.

7) Crabb DW, Stein PM, Dipple KM, Hittle JB, Sidhu R, Qulali M, Zhang K, Edenberg HJ. 1989. Structure and expression of the rat class I alcohol dehydrogenase gene. Genomics 5: 906-914.

8) Rachamin G, Macdonald JA, Wahid S, Clapp JJ, Khanna JM, Israel Y. 1980. Modulation of alcohol dehydrogenase and ethanol metabolism by sex hormones in the spontaneously hypertensive rat. Biochem $J$ 186: 483-490.

9) Crabb DW, Morzorati S, Simon J, Li T-K. 1985. Central nervous system control of liver alcohol dehydrogenase activity in rats. Life Sci 37: 2381-2387.

10) Crabb DW, Bosron WF, Li T-K. 1986. Role of the pituitary and neonatal androgenic imprinting in the hormonal regulation of liver alcohol dehydrogenase activity. Biochem Pharmacol 35: 1527-1532.

11) Teschke R, Heymann K. 1982. Effect of sex hormones on the activities of hepatic alcohol-metabolizing enzymes in male rats. Enzyme 28: 268-277.

12) Mezey E, Potter JJ, Harmon SM, Tsitouras PD. 1980. Effects of castration and testosterone administration on rat liver alcohol dehydrogenase activity. Biochem Pharmacol 29: 3175-3180.

13) Mezey E, Potter JJ. 1982. Effect of dihydrotestosterone on rat liver alcohol dehydrogenase activity. Hepatology 2: 359-365.

14) Potter JJ, Cheneval D, Dang CV, Resar LMS, Mezey E, Yang VW. 1991. The upstream stimulatory factor binds to and activates the promoter of the rat class I alcohol dehydrogenase gene. J Biol Chem 266: 15457-15463.

15) Rachamin G, Israel Y. 1985. Sex differences in hepatic alcohol dehydrogenase activity in animal species. Biochem Pharmacol 34: 2385-2386.

16) Cicero TJ, Newman KS, Schmoeker PF, Meyer ER. 1982. Role of testosterone in ethanol- and morphine-induced increases in the alcohol dehydrogenase-dependent metabolism of ethanol in the male rat. $J$ Pharmacol Exp Ther 222: 20-28.

17) Mezey E, Potter JJ. 1981. Effects of thyroidectomy and triiodothyronine administration on rat liver alcohol dehydrogenase. Gastroenterology 80: 566-574.

18) Potter JJ, Yang VW, Mezey E. 1989. Influence of growth hormone on the synthesis 
of rat liver alcohol dehydrogenase in primary hepatocyte culture. Arch Biochem Biophys 274: 548-555.

19) Qulali M, Crabb DW. 1992. Corticosterone induces rat liver alcohol dehydrogenase mRNA but not enzyme protein on activity. Alcohol Clin Exp Res 16: 427-431.

20) Mezey E, Potter JJ, Litt MR, Rhodes D. 1988. Influence of epinephrine on alcohol dehydrogenase activity in rat hepatocyte culture. Biochem Pharmacol 37: 2993-3000.

21) Mezey E, Potter JJ, Rhodes DL. 1986. Effect of growth hormone on alcohol dehydrogenase activity in hepatocyte culture. Hepatology 6: 1386-1390.

22) Mezey E, Potter JJ, Kventnansky R. 1979. Effect of stress by repeated immobilization on hepatic alcohol dehydrogenase activity and ethanol metabolism. Biochem Pharmacol 28: $657-663$.

23) Lumeng L, Bosron WF, Li T-K. 1979. Quantitative correlation of ethanol elimination rates in vivo with liver alcohol dehydrogenase activities in fed, fasted and food-restricted rats. Biochem Pharmacol 28: 1547-1551.

24) Mezey E, Potter JJ. 1985. Effect of castration on the turnover of rat liver alcohol dehydrogenase. Biochem Pharmacol 34: 369-372.

25) Tachiyashiki K, Imaizumi K. 1995. Effects of orchiectomy or ovariectomy and testosterone administration on rat liver cytosolic alcohol dehydrogenase. Jpn J Physiol 45 (Suppl 1): S252.

26) Imaizumi K, Tachiyashiki K. 1996. A possible mechanism for the sex-difference in rat liver cytosolic alcohol dehydrogenase activities. Jpn J Physiol 46 (Suppl): S208.

27) Mezey E, Potter JJ. 1979. Rat liver alcohol dehydrogenase activity: Effects of growth hormone and hypophysectomy. Endocrinology 104: 1667-1673.

28) Tachiyashiki K, Imaizumi K, Ogita Z-I. 1987. Alcohol dehydrogenase activity in the rats liver of different portion, sex and age. Nippon Eiyo Shokuryou Gakkaishi ( $J$ Jpn Soc Nutr Food Sci) 40: 207-212.

29) Tachiyashiki K, Imaizumi K. 1992. Lowering and delaying actions of bovine bile on plasma ethanol levels in rats. $J$ Nutr Sci Vitaminol 38: 69-82.

30) Tachiyashiki K, Imaizumi K. 1993. Effects of vegetable oils and $\mathrm{C}_{18}$-unsaturated fatty acids on plasma ethanol levels and gastric emptying in ethanol-administered rats. $J$ Nutr Sci Vitaminol 39: 163-176.

31) The Physiological Society of Japan. 1990. Guiding Principle for the Care and Use of Animals in the Field of Physiological Sciences, The Physiological Society of Japan, Tokyo.

32) Teschke R, Wannagat F-J, Lowendorf F, Strohmeyer G. 1986. Hepatic alcohol metabolizing enzymes after prolonged administration of sex hormones and alcohol in female rats. Biochem Pharmacol 35: 521-527.

33) Boehringer Mannheim GmbH. 1975. Alcohol dehydrogenase (ADH : alcohol: NAD ${ }^{+}$ oxidoreductase, EC 1.1.1.1). In: Biochemica Information II, p 25-26. Boehringer Mannheim $\mathrm{GmbH}$, Biochemica, Mannheim.

34) Bergmeyer HU, Gawehn K, Grassl M. 1974. Enzymes as biochemical reagents: alcohol dehydrogenase. In: Methods of Enzymatic Analysis (Bergmeyer HU, ed), Vol 1, Section B, p 428-429. Academic Press, New York and London.

35) Crow KE, Hardman MJ. 1989. Regulation of rates of ethanol metabolism. In: Human Metabolism of Alcohol-Regulation, Enzymology, and Metabolites of Ethanol(Crow KE, Batt RD, eds), Vol 2, p 3-16. CRC Press, Boca Raton, Florida.

36) Lowry OH, Rosebrough NJ, Farr AL, Randall RJ. 1951. Protein measurement with the Folin phenol reagent. $J$ Biol Chem 193: 265-275. 
37) Crabb DW. 1989. Hormonal regulation of alcohol dehydrogenase activity. In: Human Metabolism of Alcohol-Regulation, Enzymology, and Metabolites of Ethanol(Crow KE, Batt RD, eds), Vol 2, p 31-40. CRC Press, Boca Raton, Florida.

38) Mezey E, Potter JJ. 1978. Alcohol dehydrogenase activity in the uremic rat. Life Sci 22: 1985-1992.

39) Mezey E, Potter JJ, Kvetńanský R. 1979. Effect of stress by repeated immobilization on hepatic alcohol dehydrogenase activity and ethanol metabolism. Biochem Pharmacol 28: 657-663.

40) Cicero TJ, Bernard JD, Newman K. 1980. Effects of castration and chronic morphine administration on liver alcohol dehydrogenase and the metabolism of ethanol in the male Sprague-Dawley rat. J Pharmacol Exp Ther 215: 317-324. 